\title{
Vollautomatisches Lackinspektionssystem
}

\author{
Je später ein Lackdefekt bei der Automobilproduktion erkannt wird, desto höher sind die Kosten für die
} Beseitigung. Das vollautomatische Lackinspektionssystem, das von Micro-Epsilon in Kooperation mit BMW und der Universität Passau entwickelt wurde, erlaubt eine 100-Prozent-Kontrolle der Oberfläche. Das Unternehmen erhielt dafür den Innovationspreis Bayern 2014.

A m 10. November 2014 zeichnete das Bayerische Staatsministerium Micro-Epsilon für das Oberflächeninspektionssystem „Reflect-Control“ mit dem Sonderpreis in der Kategorie „Kooperation Wirtschaft-Wissenschaft“ aus. Damit würdigte die Jury insbesondere die gemeinsame Leistung im Projekt „ForsO“, das von der Bayerischen Forschungsstiftung gefördert wurde und an dem sich neben MicroEpsilon das Institut Forwiss der Universität Passau sowie das BMW-Werk Dingolfing beteiligten.

Das Oberflächeninspektionssystem erkennt automatisch kleinste Unebenheiten, Einschlüsse und Rauigkeiten und sichert eine 100-Prozent-Qualitätskontrolle industrieller spiegelnder Oberflächen im Linientakt. Das vollautomatische System erlaubt eine quantitative Analyse von Defekten und bietet eine hohe Sensitivität.

Im Vergleich zur bisherigen manuellen Prüfung hat das System deutliche Vorteile: Kleinste Oberflächenfehler werden mit konstant hoher Zuverlässigkeit erkannt. Somit wird die kostspielige Nacharbeit an Automobilkarossen minimiert. Das Inspektionssystem wird auf mehreren parallel arbeitenden Robotern installiert und so erfolgreich in der Seri-

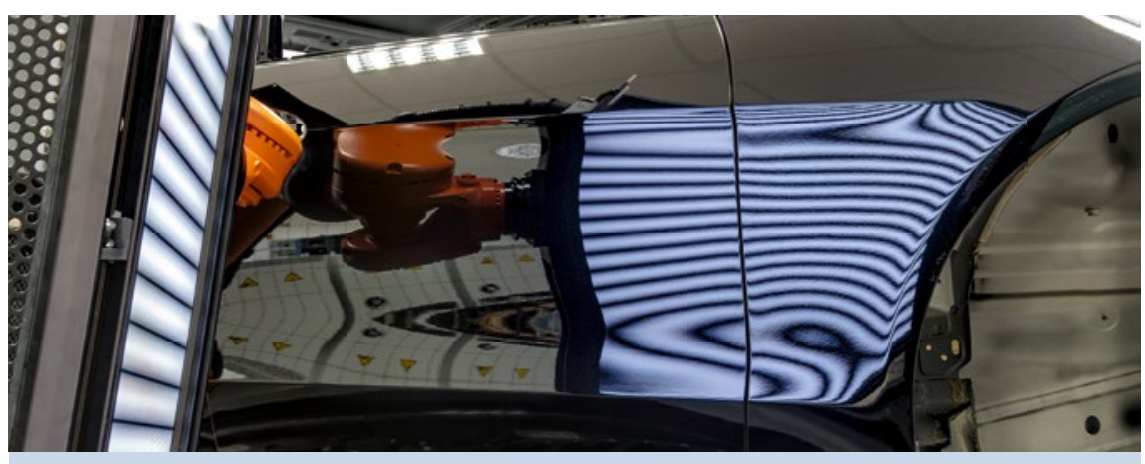

Das Messprinzip des vollautomatischen Lackinspektionssystems kann überall eingesetzt werden, wo reflektierende oder glänzende Oberflächen auf Fehler überprüft werden müssen

enproduktion in der Automobilbranche zur Lackfehlerkontrolle eingesetzt.

In Verbindung mit komplexen Bildverarbeitungsalgorithmen erkennt das Lackinspektionssystem alle Defekte, die typischerweise auf der Fahrzeugkarosserie zu finden sind, wie zum Beispiel Einschlüsse oder Wölbungen, einlackierte Fusseln oder Haare, Kleberückstände, Sprenkelungen, Krater, Lackablösungen, Lacktropfen, Läufer, Nadelstiche und vieles mehr.

Generell kann die Technologie überall dort genutzt werden, wo spiegelnde und glänzende Oberflächen auf Fehler überprüft werden müssen. Weitere mögliche Einsatzgebiete sind die
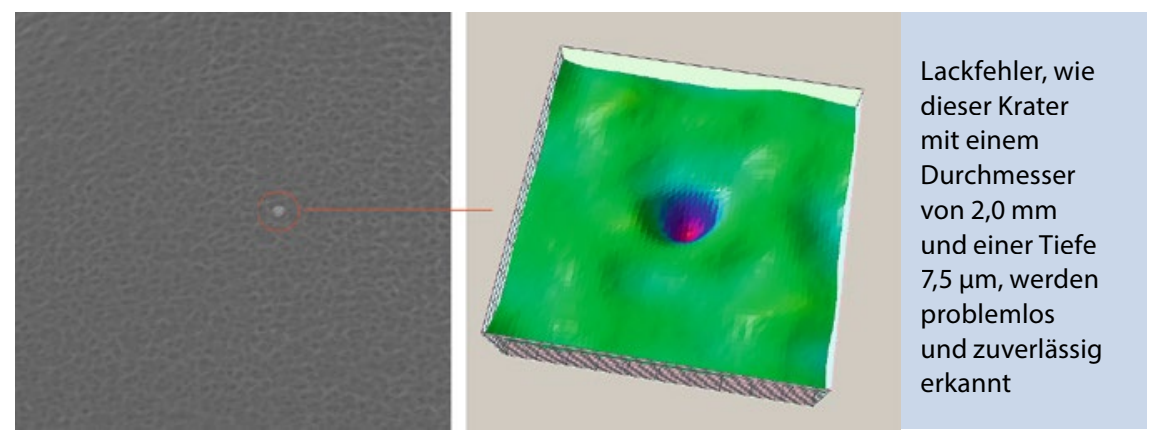

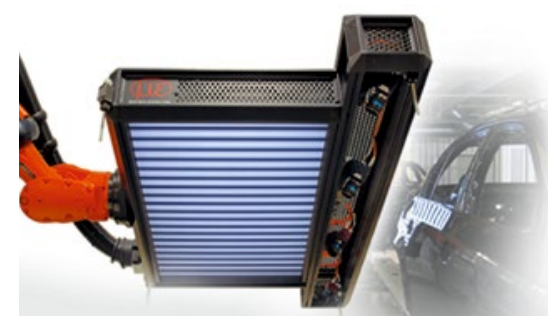

Die Lackfehlerkontrolle erfolgt mittels eines industrietauglichen DeflektometrieSensors

Oberflächenqualitätskontrolle von Displays oder von Präzisionsoptiken, die beispielsweise in modernsten Weltraumteleskopen zum Einsatz kommen.

Das Oberflächeninspektionssystem Reflect-Control Automotive ist in mehreren Linien im 3-Schicht-Betrieb zur Lackfehlerkontrolle von 100 Prozent der gefertigten Modelle im Einsatz. Die Anlage läuft zur vollsten $\mathrm{Zu}$ friedenheit des Kunden.

\section{Kontakt:}

Dieter Herzog, Vertrieb Oberflächeninspektionssysteme Micro-Epsilon Messtechnik GmbH \& Co. KG,

Ortenburg, Tel. 08542 168-100

dieter.herzog@micro-epsilon.de,www.micro-epsilon.de 